Check for updates

Cite this: RSC Adv., 2019, 9, 21679

Received 11th June 2019

Accepted 28th June 2019

DOI: $10.1039 / c 9 r a 04368 c$

rsc.li/rsc-advances

\section{In situ autologous growth of self-supporting NiFe- based nanosheets on nickel foam as an efficient electrocatalyst for the oxygen evolution reaction $\uparrow$}

\author{
Jianying Wang, ${ }^{a}$ Xue Teng, ${ }^{a}$ Yanli Niu, ${ }^{a}$ Lixia Guo, ${ }^{a}$ Jianfei Kong, ${ }^{b}$ Xiaoming $\mathrm{He}\left({ }^{a}{ }^{a}\right.$ \\ and Zuofeng Chen (D) *ac
}

\begin{abstract}
A highly efficient and low-cost oxygen evolution reaction electrocatalyst is essential for water splitting. Herein, a simple and cost-effective autologous growth method is developed to prepare Nife-based integrated electrodes for water oxidation. In this method, a $\mathrm{Ni}(\mathrm{OH})_{2}$ nanosheet film is first developed on nickel foam by oxidative deposition in a chemical bath solution. The as-prepared nanosheet electrode is then immersed into a solution containing Fe(III) cations to form an Fe-doped $\mathrm{Ni}(\mathrm{OH})_{2}$ electrode by utilization of the different solubility of metal cations. Benefiting from its unique and integrated nanostructure, this hierarchically structured electrode displays extremely high catalytic activity toward water oxidation. In $1 \mathrm{M} \mathrm{KOH}$, the electrode can deliver a current density of $1000 \mathrm{~mA} \mathrm{~cm}^{-2}$ at an overpotential of only $330 \mathrm{mV}$. This work provides a facile way to produce an efficient, durable, and Earth-abundant OER electrocatalyst with no energy input, which is attractive for large-scale water splitting.
\end{abstract}

\section{Introduction}

Water splitting to produce hydrogen fuels represents one of the most appealing strategies to obtain clean and sustainable energy. ${ }^{1,2}$ The water splitting reaction can be classified into two half cell reactions: the hydrogen evolution reaction (HER) and the oxygen evolution reaction (OER). ${ }^{3,4}$ As one of the half reactions, OER has more sluggish kinetics and requires higher overpotentials than the relatively simple HER, since it involves the removal of $4 \mathrm{e}^{-}$and $4 \mathrm{H}^{+}$from two water molecules to generate one oxygen molecule. ${ }^{5}$ As a result, the large overpotential of the OER greatly increases the overall energy input of the water splitting. ${ }^{6}$ To reduce the overpotential loss of the OER, the development of cost-effective, high-performance OER electrocatalysts is urgently required.

Over the past decade, extensive efforts have been devoted to develop OER catalysts based on the first-row transition nonprecious metals. ${ }^{7-10}$ Among these Earth-abundant materials, nickel-iron-based electrocatalysts have attracted much attention owing to their high OER activity. ${ }^{11-13}$ It has now been wellestablished that incorporation of $\mathrm{Fe}$ into $\mathrm{Ni}$ composite can

\footnotetext{
${ }^{a}$ Shanghai Key Lab of Chemical Assessment and Sustainability, School of Chemical Science and Engineering, Tongji University, Shanghai 200092, China. E-mail: zfchen@tongji.edu.cn

${ }^{b}$ Jiangsu Vocational College of Medicine, Yancheng 224005, Jiangsu Province, China ${ }^{c}$ College of Chemistry and Materials Science, Longyan University, Longyan, Fujian, 364012, China

$\dagger$ Electronic supplementary information (ESI) available. See DOI: $10.1039 / \mathrm{c} 9 \mathrm{ra} 04368 \mathrm{c}$
}

significantly enhance the catalytic activity for water oxidation, since the conductivity and charge transfer of NiFe-based electrocatalyst can be dramatically increased by taking the advantage of synergistic metal-metal interactions. ${ }^{14-16}$ In earlier studies, these catalyst materials are usually prepared by electrodeposition or hydrothermal reaction methods followed by casting onto the electrode substrate surface. ${ }^{17-21}$ These strategies however may result in several problems, such as high energy input during the catalyst preparation, slow charge transfer between catalyst and electrode substrate and poor stability under vigorous $\mathrm{O}_{2}$ evolution conditions. ${ }^{22-24}$

To overcome these obstacles, some integrated electrodes prepared by in situ self-growth method were reported recently. ${ }^{22-26}$ For example, Cao et al. reported an integrated NiFebased electrode by a surface oxidation method, and Zheng et al. developed a combinatorial self-regulated acidic etching and topotactic selenization method for preparation of electrocatalysts. ${ }^{22,26}$ Recently, the Chen group and the Zou group reported respectively NiFe-based integrated electrodes by the spontaneous galvanic replacement reaction with an iron foam in $\mathrm{Ni}$ (II) solution, which show excellent catalytic activity for OER. ${ }^{23,24}$ These in situ self-growth strategies can simplify the fabrication procedures, lower the production costs and enhance catalytic activities and stabilities of NiFe-based electrocatalysts.

Herein, we report a NiFe-based OER electrocatalyst prepared by oxidative deposition of nickel foam in a chemical bath solution followed by an ion-exchange treatment. The fabrication procedure is simple and cost-effective without complex instrumentation, predesigned templates and extraneous nickel source. The fabrication process of the NiFe-based electrode 


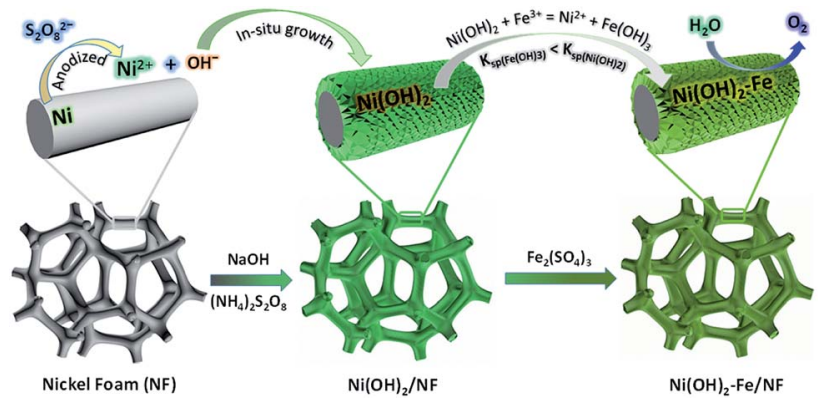

Scheme 1 Fabrication process of the $\mathrm{Ni}(\mathrm{OH})_{2}-$ Fe electrodes and their utilization for water oxidation.

materials for water oxidation is illustrated in Scheme 1. A NiFebased electrocatalyst film with uniform nanosheets was formed on the nickel foam surface. The integrated electrode exhibits a hierarchical structure with large specific surface area and high catalytic activity and durability toward OER in alkaline media. In $1 \mathrm{M} \mathrm{KOH}$, the electrode can deliver a very high current density of $1000 \mathrm{~mA} \mathrm{~cm}{ }^{-2}$ at an overpotential of only $330 \mathrm{mV}$.

\section{Experimental}

\section{Materials}

Ferric sulfate $\left(\mathrm{Fe}_{2}\left(\mathrm{SO}_{4}\right)_{3}, 98 \%\right)$, potassium hydroxide $(\mathrm{KOH}$, $99 \%)$, sodium hydroxide ( $\mathrm{NaOH}, 99 \%)$, ammonium persulfate $\left(\left(\mathrm{NH}_{4}\right)_{2} \mathrm{~S}_{2} \mathrm{O}_{8}, 98 \%\right)$; hydrochloric acid $(\mathrm{HCl})$ and ethanol $\left(\mathrm{C}_{2} \mathrm{H}_{5} \mathrm{OH}, 99.8 \%\right)$ were obtained from Sigma Aldrich. Nickel foam (NF, thickness $\sim 0.5 \mathrm{~mm}$, bulk density $\sim 0.56 \mathrm{~g} \mathrm{~cm}^{-3}$ ) was obtained from Shanxi Lizhiyuan Material of Battery Co. Ltd (China). All other reagents were analytical grade and used as received. All electrolyte solutions were prepared with deionized water $(18 \mathrm{M} \Omega \mathrm{cm})$ unless stated otherwise.

\section{Preparation of $\mathrm{Ni}(\mathrm{OH})_{2}-\mathrm{Fe} / \mathrm{NF}$ electrodes}

The nickel foam $\left(1 \times 3 \mathrm{~cm}^{2}\right)$ was firstly cleaned by ultrasonication in $1 \mathrm{M} \mathrm{HCl}$ solution for $2 \mathrm{~h}$ to remove the organic impurities and oxides on the surface, and then cleaned in ethanol ( $5 \mathrm{~min}$ ) and deionized water $(5 \mathrm{~min})$ in sequence by ultrasonication, respectively. The nickel foam was stored in a glass bottle for $24 \mathrm{~h}$ at room temperature. Then, the nickel foam was taken out and immersed in mixed solution of $\left(\mathrm{NH}_{4}\right)_{2} \mathrm{~S}_{2} \mathrm{O}_{8}(5 \mathrm{~mL}, 1 \mathrm{M})$ and $\mathrm{KOH}(10 \mathrm{~mL}, 3 \mathrm{M})$ in a $20 \mathrm{~mL}$ transparent bottle for $8 \mathrm{~h}$ under the ambient temperature. The resultant electrode was washed with deionized water thoroughly and named as $\mathrm{Ni}(\mathrm{OH})_{2} / \mathrm{NF}$ electrode. The as-prepared $\mathrm{Ni}(\mathrm{OH})_{2} /$ $\mathrm{NF}$ electrode was then placed in a solution containing $20 \mathrm{mM}$ $\mathrm{Fe}_{2}\left(\mathrm{SO}_{4}\right)_{3}$ aqueous solution. The $\mathrm{Ni}(\mathrm{OH})_{2} / \mathrm{NF}$ electrode had an exposure geometric surface area of $2 \mathrm{~cm}^{2}$ in the solution. The reaction between $\mathrm{Fe}(\mathrm{III})$ and $\mathrm{Ni}(\mathrm{OH})_{2}$ was processed under the ambient temperature. The resultant electrode was washed with deionized water thoroughly and named as $\mathrm{Ni}(\mathrm{OH})_{2}-\mathrm{Fe} / \mathrm{NF}$ electrode.

\section{Characterizations}

Scanning electron microscope (SEM) images, energy dispersive X-ray spectroscopy analysis (EDX) data and EDX mapping images were obtained at Hitachi S-4800 (Hitachi, Japan) equipped with a Horiba EDX system. Transmission electron microscopy (TEM) images, high resolution TEM (HRTEM) images and selected area electron diffraction (SAED) image were obtained using JEM-2100, JEOL. The NiFe-based nanosheets catalyst was removed from the $\mathrm{Ni}(\mathrm{OH})_{2}-\mathrm{Fe} / \mathrm{NF}$ electrode substrate by sonication in the absolute ethanol, and a drop of the mixture was dried on a the micro grid copper network for analysis. Powder X-ray diffraction (XRD) was measured by Bruker D8 Focus via ceramic monochromatized $\mathrm{Cu} \mathrm{K} \alpha$ radiation of $1.54178 \AA$, operating at $40 \mathrm{kV}$ and $40 \mathrm{~mA}$. Raman spectra were recorded on a confocal microscope laser Raman spectrometer (Reinshaw invia). X-ray photoelectron spectroscopy (XPS) for elemental analysis was conducted on a Kratos Axis Ultra DLD Xray Photoelectron Spectrometer using $60 \mathrm{~W}$ monochromated $\mathrm{Mg} \mathrm{K} \alpha$ radiation as the X-ray source for excitation. The carbon 1s peak (284.6 eV) was used for internal calibration. The peak resolution and fitting were processed by XPS Peak 41 software.

\section{Electrochemical measurements}

Electrochemical measurements were performed on a CHI 660E electrochemical workstation (Chenhua Corp., Shanghai, China). The three-electrode system consisted of a working electrode, a platinum plate counter electrode, and a saturated calomel reference electrode (SCE, $\sim 0.244 \mathrm{~V} v s$. NHE). Unless stated otherwise, all potentials in cyclic voltammetry were reported $v s$. RHE with $80 \%$ iR compensation and all controlled potential electrolysis and chronopotentiometry experiments were conducted without iR compensation. All experiments were performed at $22 \pm 2{ }^{\circ} \mathrm{C}$.

\section{Results and discussion}

\section{Characterizations of $\mathrm{Ni}(\mathrm{OH})_{2}-\mathrm{Fe} / \mathrm{NF}$ electrodes}

As illustrated in Scheme 1, the $\mathrm{Ni}(\mathrm{OH})_{2}$ nanosheet electrode is firstly prepared by oxidation of a fresh nickel foam in a mixed solution containing $\left(\mathrm{NH}_{4}\right)_{2} \mathrm{~S}_{2} \mathrm{O}_{8}$ and $\mathrm{NaOH}$. In the second step, the as-prepared $\mathrm{Ni}(\mathrm{OH})_{2}$ nanosheet electrode is immersed into a solution containing $\mathrm{Fe}(\mathrm{III})$ ions for different times at room temperature. Due to the different water solubility of $\mathrm{Ni}(\mathrm{OH})_{2}$ and $\mathrm{Fe}(\mathrm{OH})_{3}\left(K_{\mathrm{sp}\left(\mathrm{Fe}(\mathrm{OH})_{3}\right)}=2.6 \times 10^{-39}<K_{\mathrm{sp}\left(\mathrm{Ni}(\mathrm{OH})_{2}\right)}=5.0 \times\right.$ $\left.10^{-16}\right)$, parts of $\mathrm{Ni}(\mathrm{II})$ in $\mathrm{Ni}(\mathrm{OH})_{2}$ nanosheets are replaced by $\mathrm{Fe}(\mathrm{III})$ in the solution, which forms the Fe-doped $\mathrm{Ni}(\mathrm{OH})_{2}$ nanosheet electrodes.

The morphology of the as-prepared electrodes was firstly investigated by scanning electron microscopy (SEM). Fig. 1A and $\mathrm{B}$ show that a uniform film of $\mathrm{Ni}(\mathrm{OH})_{2}$ nanosheets is formed on the electrode substrate after the oxidative deposition treatment. After immersion in $20 \mathrm{mM}$ Fe(III) solution for $5 \mathrm{~min}$, Fig. 1C displays that the resultant $\mathrm{Ni}(\mathrm{OH})_{2}-\mathrm{Fe} / \mathrm{NF}$ electrode maintains the uniform morphology of nanosheet structure. The SEM images of the $\mathrm{Ni}(\mathrm{OH})_{2}-\mathrm{Fe} / \mathrm{NF}$ electrodes prepared by different immersion times are also provided. As shown in 

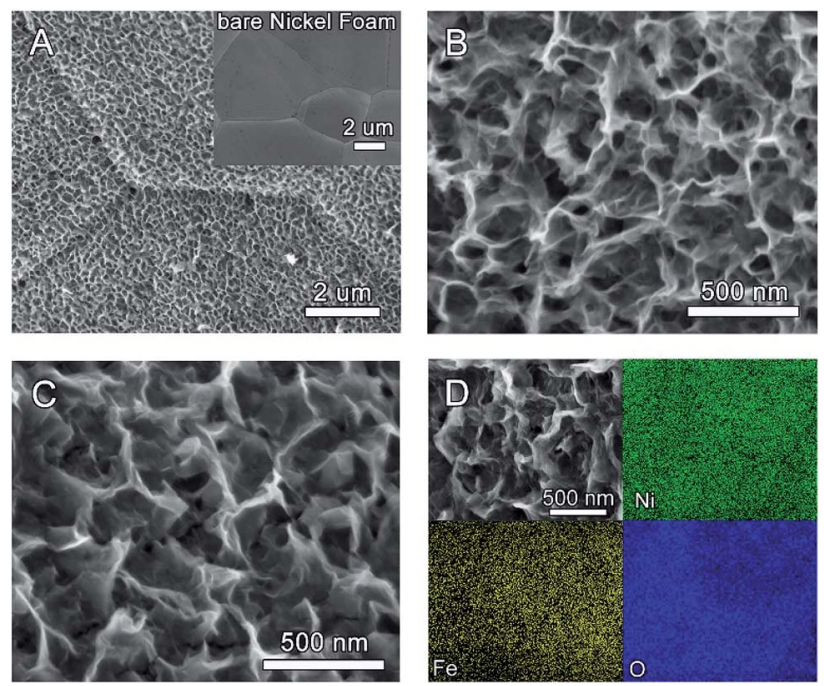

Fig. 1 (A and B) SEM images of different magnifications for $\mathrm{Ni}(\mathrm{OH})_{2}$ nanosheets grown from nickel foam (inset is SEM image of a bare nickel foam). (C) SEM and (D) SEM-EDX mapping images of the $\mathrm{Ni}(\mathrm{OH})_{2}-\mathrm{Fe} / \mathrm{NF}$ electrode.

Fig. S1, $\uparrow$ the nanosheet structure of the electrode is destroyed after immersion in $\mathrm{Fe}(\mathrm{III})$ solution for a prolonged time of $10 \mathrm{~min}$, indicating an important effect of the immersion time on the structure of the prepared electrode. The SEM-energy dispersive X-ray spectroscopy (EDX) measurement was conducted to probe the elemental composition and distribution in the $\mathrm{Ni}(\mathrm{OH})_{2}-\mathrm{Fe} / \mathrm{NF}$ electrode. In Fig. $\mathrm{S} 2, \uparrow$ the elemental analysis reveals that the nanosheet material is composed of $\mathrm{Ni}, \mathrm{Fe}$ and $\mathrm{O}$ elements. Moreover, the elemental mapping images show that these elements are distributed uniformly within the nanosheets, as shown in Fig. 1D.

To further investigate the morphology structure of the $\mathrm{Ni}(\mathrm{OH})_{2}-\mathrm{Fe} / \mathrm{NF}$ electrode, the transmission electron microscopy (TEM) test was also conducted. As shown in Fig. S3, $\dagger$ the nanosheet structure could be clearly observed. The selectedarea electron diffraction (SAED) pattern in Fig. S3A $\dagger$ inset indicates the amorphous or low-crystallinity structure of the nanosheet material. Accordingly, the high-resolution TEM (HRTEM) image in Fig. S3B $\uparrow$ also presents the amorphous structure with no visible lattice fringes in the nanosheet, consistent with the SAED pattern.

The bulk crystallity and surface composition of the hierarchical electrodes were characterized by X-ray diffraction (XRD). In Fig. $\mathrm{S} 4, \uparrow$ the XRD patterns of the $\mathrm{Ni}(\mathrm{OH})_{2} / \mathrm{NF}$ and $\mathrm{Ni}(\mathrm{OH})_{2}-$ $\mathrm{Fe} / \mathrm{NF}$ electrodes exhibit three diffraction peaks located at $44.5^{\circ}$, $51.8^{\circ}$, and $76.4^{\circ}$, respectively, which can be assigned to the (111), (200) and (220) planes of cubic Ni (PDF\# 04-0850). ${ }^{17}$ No other diffraction peaks are observed in the XRD patterns, indicating the amorphous or low-crystallinity structure of the both $\mathrm{Ni}(\mathrm{OH})_{2}$ and $\mathrm{Ni}(\mathrm{OH})_{2}-\mathrm{Fe}$ nanosheet materials, which is consistent with TEM results. ${ }^{17}$

Fig. 2A shows Raman spectra of the $\mathrm{Ni}(\mathrm{OH})_{2} / \mathrm{NF}$ and $\mathrm{Ni}(\mathrm{OH})_{2}-\mathrm{Fe} / \mathrm{NF}$ electrodes. As the electrode background, no Raman signal is detected for the bare nickel foam. At the
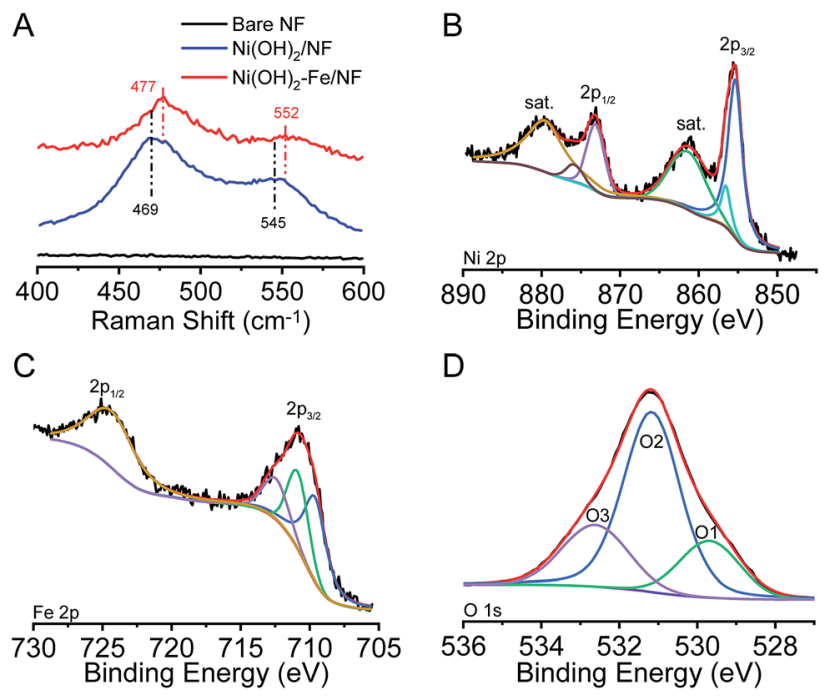

Fig. 2 (A) Raman spectra of the bare nickel foam, $\mathrm{Ni}(\mathrm{OH})_{2} / \mathrm{NF}$ and $\mathrm{Ni}(\mathrm{OH})_{2}-\mathrm{Fe} / \mathrm{NF}$ electrodes. The high-resolution XPS of $\mathrm{Ni} 2 \mathrm{p}(\mathrm{B}), \mathrm{Fe} 2 \mathrm{p}$ (C) and $\mathrm{O}$ 1s (D) of the $\mathrm{Ni}(\mathrm{OH})_{2}-\mathrm{Fe} / \mathrm{NF}$ electrode.

$\mathrm{Ni}(\mathrm{OH})_{2} / \mathrm{NF}$ electrode, the Raman spectrum exhibits a pair of broad peaks located at 469 and $543 \mathrm{~cm}^{-1}$, which are attributed to $\mathrm{Ni}-\mathrm{O}$ vibrations in NiOOH. ${ }^{\mathbf{1 4 - 1 6}}$ At the $\mathrm{Ni}(\mathrm{OH})_{2}-\mathrm{Fe} / \mathrm{NF}$ electrode, these two peaks shift to 477 and $552 \mathrm{~cm}^{-1}$, which is consistent with the incorporation of the $\mathrm{Fe}^{3+}$ cations into the $\mathrm{Ni}(\mathrm{OH})_{2}$ nanosheets. ${ }^{\mathbf{1 4 - 1 6}}$

Fig. S5 $\uparrow$ shows the survey X-ray photoelectron spectroscopy (XPS) of the $\mathrm{Ni}(\mathrm{OH})_{2}-\mathrm{Fe} / \mathrm{NF}$ electrode, revealing the $\mathrm{Fe}, \mathrm{Ni}$ and $\mathrm{O}$ elements on the electrode surface with an atomic ratio of $\sim 2: 1$ for Ni : Fe. Fig. 2B-D show the high-resolution XPS of Ni 2p, Fe $2 \mathrm{p}$, and $\mathrm{O} 1 \mathrm{~s}$, respectively. In Ni 2p XPS, two dominant peaks are observed at binding energies of 855.5 and $873.1 \mathrm{eV}$ for Ni $2 \mathrm{p}_{1 / 2}$ and $\mathrm{Ni} 2 \mathrm{p}_{3 / 2}$, which are accompanied by two less intense satellite peaks, consistent with the presence of divalent $\mathrm{Ni}^{12,24}$ In $\mathrm{Fe}$ 2p XPS, two dominant peaks are located at 710.9 and $725.0 \mathrm{eV}$, indicating the presence of trivalent $\mathrm{Fe}^{22,27,28}$ The highresolution XPS of $\mathrm{O}$ 1s exhibits the existence of three oxygen contributions, which are denoted as $\mathrm{O} 1, \mathrm{O} 2$, and $\mathrm{O} 3$, respectively. Specifically, the fitting peak of O1 at $529.7 \mathrm{eV}$ is typical of metal-oxygen bonds. ${ }^{27,29,30}$ The $\mathrm{O} 2$ located at $531.1 \mathrm{eV}$ is usually associated with oxygen in hydroxyl groups. ${ }^{27,29,30}$ The O3 appeared at $532.6 \mathrm{eV}$ can be assigned to oxygen species in the surface-adsorbed $\mathrm{H}_{2} \mathrm{O}$ molecule. ${ }^{24,27}$ All the analysis results indicate that the NiFe co-doping double-hydroxide material has been successfully prepared.

\section{Electrocatalytic OER performance}

The electrocatalytic activity of the electrodes toward water oxidation were evaluated in a typical three-electrode setup in 1.0 $\mathrm{M} \mathrm{KOH}$ with Pt-plate as the counter electrode and saturated calomel electrode as the reference electrode. Fig. 3A shows cyclic voltammetry $(\mathrm{CV})$ plots of the bare nickel foam, $\mathrm{Ni}(\mathrm{OH})_{2} /$ $\mathrm{NF}$ and $\mathrm{Ni}(\mathrm{OH})_{2}-\mathrm{Fe} / \mathrm{NF}$ electrodes toward water oxidation. Obviously, in comparison with bare $\mathrm{NF}$ and $\mathrm{Ni}(\mathrm{OH})_{2} / \mathrm{NF}$ 

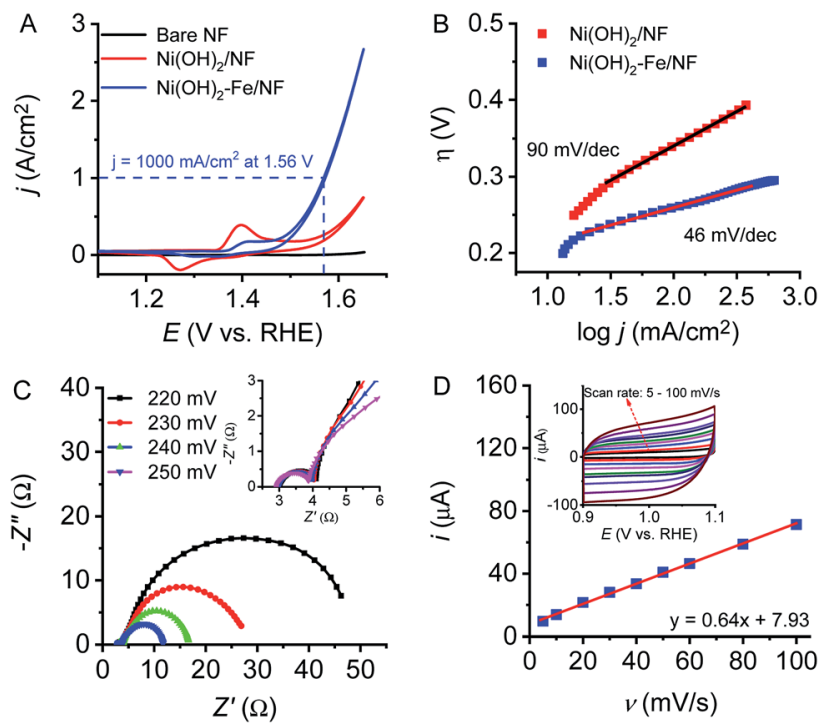

Fig. 3 (A) $\mathrm{CV}$ plots of a bare nickel foam (NF), Ni(OH) $/ 2 \mathrm{NF}$ and $\mathrm{Ni}(\mathrm{OH})_{2}-\mathrm{Fe} / \mathrm{NF}$ electrodes. (B) Tafel plots of the $\mathrm{Ni}(\mathrm{OH})_{2} / \mathrm{NF}$ and $\mathrm{Ni}(\mathrm{OH})_{2}-\mathrm{Fe} / \mathrm{NF}$ electrodes. (C) Nyquist plots of $\mathrm{Ni}(\mathrm{OH})_{2}-\mathrm{Fe} / \mathrm{NF}$ electrode at various overpotentials; inset shows the high-frequency regions. (D) The anodic charging current at $1.0 \mathrm{~V}$ vs. RHE, plotted against the scan rates of $\mathrm{Ni}(\mathrm{OH})_{2}-\mathrm{Fe} / \mathrm{NF}$ electrode; inset shows the corresponding CVs curves.

electrodes, the $\mathrm{Ni}(\mathrm{OH})_{2}-\mathrm{Fe} / \mathrm{NF}$ electrode displays a significantly enhanced OER catalytic activity with an onset overpotential of $210 \mathrm{mV}$ and an overpotential of $330 \mathrm{mV}$ to deliver an extremely large current density of $1000 \mathrm{~mA} \mathrm{~cm}{ }^{-2}$. This excellent OER performance with large catalytic current density at small overpotential outperforms most reported state-of-the-art OER electrocatalysts, as shown in Table 1 . It is noting that CVs of the $\mathrm{Ni}(\mathrm{OH})_{2} / \mathrm{NF}$ and $\mathrm{Ni}(\mathrm{OH})_{2}-\mathrm{Fe} / \mathrm{NF}$ electrodes feature an apparent prewave before the catalytic OER onset, consistent with conversion of divalent $\mathrm{Ni}$ to trivalent Ni. The decreased intensity of this prewave and the enhanced catalytic activity of the $\mathrm{Ni}(\mathrm{OH})_{2}-\mathrm{Fe} / \mathrm{NF}$ electrode indicates that the Fe-doped $\mathrm{Ni}(\mathrm{OH})_{2}$ nanosheet electrode has been successfully fabricated by this strategy. The catalytic activities of the $\mathrm{Ni}(\mathrm{OH})_{2}-\mathrm{Fe} / \mathrm{NF}$ electrodes prepared by varying the immersion time are shown in Fig. S6. $\dagger$ The catalytic current density increases rapidly at the initial time, and then decreases by further extending the immersion time. With an optimized immersion time of $5 \mathrm{~min}$, it reaches the maximum value. In contrast, the redox prewave is decreased monotonously along with the immersion time. These observations are consistent with the transformation of $\mathrm{Ni}(\mathrm{OH})_{2}$ to $\mathrm{Fe}(\mathrm{OH})_{3}$ on the electrode surface.

To evaluate the intrinsic catalytic activity of the material electrodes, Tafel plots were obtained from the polarization curves recorded at an extremely slow scan rate of $0.1 \mathrm{mV} \mathrm{s}^{-1}$ to minimize the influence of capacitive currents. According to the Tafel equation, the Tafel slope was calculated by using a linear fit applied to points in the Tafel region. As shown in Fig. 3B, the $\mathrm{Ni}(\mathrm{OH})_{2}-\mathrm{Fe} / \mathrm{NF}$ electrode displays a Tafel slope of $46 \mathrm{mV} \mathrm{dec}-1$ in $1 \mathrm{M} \mathrm{KOH}$ solution, which is lower than $\mathrm{Ni}(\mathrm{OH})_{2} / \mathrm{NF}$ electrode. Compared to previously reported three-dimensional (3D) OER systems in Table 1, this hierarchically structured electrode exhibits competitive catalytic activity under similar experimental conditions.

The electrochemical impedance spectroscopy (EIS) measurement was conducted at various overpotentials to evaluate the catalytic activity of $\mathrm{Ni}(\mathrm{OH})_{2}-\mathrm{Fe} / \mathrm{NF}$ electrode in $1 \mathrm{M}$ $\mathrm{KOH}$. Fig. 3C and the inset display the Nyquist plots obtained from the $\mathrm{Ni}(\mathrm{OH})_{2}-\mathrm{Fe} / \mathrm{NF}$ electrode at different potentials. The charge transfer resistance decreased as the overpotential increased, which is consistent with the high catalytic activity of the NiFe-based electrocatalyst. In addition, all the EIS Nyquist plots exhibit two semicircles at all applied potentials, which correspond to a two-time-constant behavior of the materials. The first one at the high frequency is associated with the porous structure of the electrode surface, while the second one at the low frequency is ascribed to the charge transfer resistance during electrocatalytic reactions. The low charge transfer resistance of the $\mathrm{Ni}(\mathrm{OH})_{2}-\mathrm{Fe} / \mathrm{NF}$ electrode is attributed to intimate contact between NiFe-based catalyst and nickel foam substrate constructed by in situ autologous growth strategy.

The electrochemical surface area (ECSA) of the $\mathrm{Ni}(\mathrm{OH})_{2}-\mathrm{Fe} /$ $\mathrm{NF}$ electrode is estimated by the charging currents recorded in cyclic voltammetry (CV) curves at $1.0 \mathrm{~V}$ vs. RHE at different scan rates in $1 \mathrm{M} \mathrm{KOH}$, as shown in Fig. 3D. The double layer capacitance is calculated from the slope of the anodic charging currents against the scan rates and a capacitance of $640 \mu \mathrm{F}$ is obtained. Based on the estimated specific capacitance $(40 \mu \mathrm{F}$

Table 1 Comparison of the electrocatalytic performance of the OER catalysts at 3D substrates in $1 \mathrm{M} \mathrm{KOH} \mathrm{solution}^{a}$

\begin{tabular}{|c|c|c|c|c|}
\hline Electrocatalyst & Onset overpotential & $\begin{array}{l}j(\mathrm{~mA} \\
\left.\mathrm{cm}^{-2}\right) @ \eta=300 \mathrm{mV}\end{array}$ & $\begin{array}{l}\text { Tafel slope } \\
\left(\mathrm{mV} \mathrm{dec}^{-1}\right)\end{array}$ & Ref. \\
\hline $\mathrm{NiFe} / \mathrm{NF}$ & $215 \mathrm{mV}$ & 300 & 28 & 17 \\
\hline $\mathrm{NiFe} / \mathrm{IF}$ & $220 \mathrm{mV}$ & 500 & 48.3 & 23 \\
\hline NiFeOx/IF & $220 \mathrm{mV}$ & 1000 & $34-36$ & 24 \\
\hline NiFe LDH/IF & $200 \mathrm{mV}$ & - & 40.4 & 25 \\
\hline $\mathrm{Ni}(\mathrm{OH})_{2}-\mathrm{Fe} / \mathrm{NF}$ & $210 \mathrm{mV}$ & 530 & 46 & This work \\
\hline
\end{tabular}

${ }^{a}$ LDH: layered double hydroxide; NF: nickel foam; IF: iron foam. 

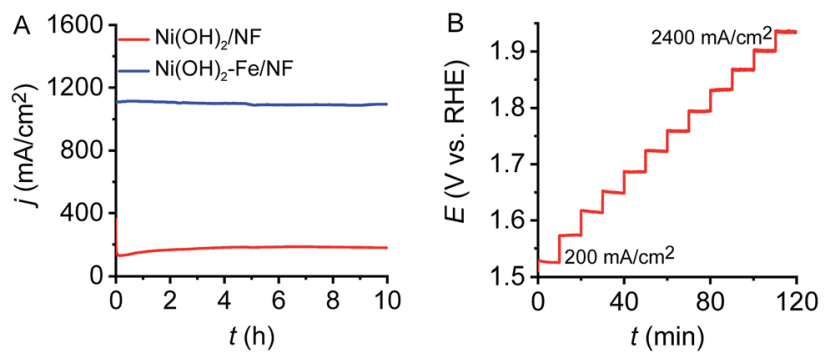

Fig. 4 (A) CPEs at $1.70 \mathrm{~V}$ vs. RHE of the $\mathrm{Ni}(\mathrm{OH})_{2} / \mathrm{NF}$ and $\mathrm{Ni}(\mathrm{OH})_{2}-\mathrm{Fe} /$ $\mathrm{NF}$ electrodes. (B) Multi-current process at the $\mathrm{Ni}(\mathrm{OH})_{2}-\mathrm{Fe} / \mathrm{NF}$ electrode.

$\mathrm{cm}^{-2}$ ) for NiFe oxides in alkaline solutions, ${ }^{22,24}$ the ECSA of the $\mathrm{Ni}(\mathrm{OH})_{2}-\mathrm{Fe} / \mathrm{NF}$ electrode is $16 \mathrm{~cm}^{2}$, indicating a high roughness factor of 160 in comparison with a planar electrode of NiFe oxides. Fig. $\mathrm{S} 7 \dagger$ displays the specific current density against the applied potentials based on the ECSA of the electrode. This hierarchically structured electrode with high roughness factor could expose abundant catalytic active sites and facilitate the dispersion of gas bubbles generated at high current densities.

To investigate the catalytic stability and activity of the electrode, a long-term controlled potential electrolysis (CPE) experiment was conducted at $1.70 \mathrm{~V}$ vs. RHE in $10 \mathrm{M} \mathrm{KOH}$. As observed in Fig. 4A, the $\mathrm{Ni}(\mathrm{OH})_{2}-\mathrm{Fe} / \mathrm{NF}$ electrode maintains its catalytic current density at $1100 \mathrm{~mA} \mathrm{~cm}^{-2}$ with negligible current loss for at least $10 \mathrm{~h}$. During the prolonged electrocatalysis process, vigorous gas bubbles were produced continuously and dispersed rapidly at the electrode surface. Unlike electrodeposited or cast catalysts on supporting substrates, the in situ autologous growth strategy developed in this study is crucial to maintain the stability of the electrode under rigorous and violent $\mathrm{O}_{2}$ evolution conditions at large current density.

A multi-step chronopotentiometry experiment was conducted to further examine the electrocatalyst stability for OER at different catalytic current densities in $10 \mathrm{M} \mathrm{KOH}$ solution. The applied current density was increased stepwise from 200 to 2400 $\mathrm{mA} \mathrm{cm}{ }^{-2}$ with an increment of $200 \mathrm{~mA} \mathrm{~cm}{ }^{-2}$ per $10 \mathrm{~min}$. As shown in Fig. 4B, the recorded potentials at each current density remain constant and no sign of deactivation is observed within the test period, indicating the high stability of the $\mathrm{Ni}(\mathrm{OH})_{2}-\mathrm{Fe} /$ NF electrode within a wide range of current density. These chronopotentiometric responses indicates efficient charge transfer and excellent mass transport properties of the 3D hierarchical $\mathrm{Ni}(\mathrm{OH})_{2}-\mathrm{Fe} / \mathrm{NF}$ electrode.

\section{Conclusions}

In summary, we report the in situ autologous growth of ultrathin $\mathrm{Ni}(\mathrm{OH})_{2}$ nanosheet with incorporation of $\mathrm{Fe}$ at ambient temperature without any energy input and its application as a high-performance OER electrocatalyst. The electrocatalytic performance of the hierarchical electrodes can be easily adjusted by varying the immersion time of $\mathrm{Ni}(\mathrm{OH})_{2}$ nanosheet in Fe(III) solution. Benefiting from its unique and integrated nanostructures, this hierarchically structured electrode displays excellent electrocatalytic activity and stability toward water oxidation. In $1 \mathrm{M} \mathrm{KOH}$, the $\mathrm{Ni}(\mathrm{OH})_{2}-\mathrm{Fe} / \mathrm{NF}$ electrode can deliver a current density of $1000 \mathrm{~mA} \mathrm{~cm} \mathrm{~cm}^{-2}$ at an overpotential of only $330 \mathrm{mV}$. The facile preparation approach with no energy input and the high performance of this Earth-abundant material electrode toward water oxidation are appealing for practical applications in large-scale water splitting.

\section{Conflicts of interest}

There are no conflicts to declare.

\section{Acknowledgements}

This work was supported by the National Natural Science Foundation of China (21573160, 21872105), the Natural Science Foundation of Jiangsu Province (BK20181211), and Science \& Technology Commission of Shanghai Municipality (14DZ2261100).

\section{Notes and references}

1 I. Roger, M. A. Shipman and M. D. Symes, Nat. Rev. Chem., 2017, 1, 1.

2 M. S. Dresselhaus and I. L. Thomas, Nature, 2001, 414, 332337.

3 X. Zou and Y. Zhang, Chem. Soc. Rev., 2015, 44, 5148-5180.

4 Y. X. Chen, K. N. Yang, B. Jiang, J. X. Li, M. Q. Zeng and L. Fu, J. Mater. Chem. A, 2017, 5, 8187-8208.

5 N. T. Suen, S. F. Hung, Q. Quan, N. Zhang, Y. J. Xu and H. M. Chen, Chem. Soc. Rev., 2017, 46, 337-365.

6 M. G. Walter, E. L. Warren, J. R. McKone, S. W. Boettcher, Q. Mi, E. A. Santori and N. S. Lewis, Chem. Rev., 2010, 110, 6446-6473.

7 J. Du, Z. Chen, S. Ye, B. J. Wiley and T. J. Meyer, Angew. Chem., Int. Ed. Engl., 2015, 54, 2073-2078.

8 L. Han, S. Dong and E. Wang, Adv. Mater., 2016, 28, 92669291.

9 M. M. Najafpour, G. Renger, M. Holynska, A. N. Moghaddam, E. M. Aro, R. Carpentier, H. Nishihara, J. J. Eaton-Rye, J. R. Shen and S. I. Allakhverdiev, Chem. Rev., 2016, 116, 2886-2936.

10 I. Roger and M. D. Symes, J. Mater. Chem. A, 2016, 4, 67246741.

11 C. Dong, T. Kou, H. Gao, Z. Peng and Z. Zhang, Adv. Energy Mater., 2018, 8, 1701347.

12 D. Zhou, S. Wang, Y. Jia, X. Xiong, H. Yang, S. Liu, J. Tang, J. Zhang, D. Liu, L. Zheng, Y. Kuang, X. Sun and B. Liu, Angew. Chem., Int. Ed. Engl., 2019, 58, 736-740.

13 J. Y. Wang, L. L. Ji and Z. F. Chen, ACS Catal., 2016, 6, 69876992.

14 M. W. Louie and A. T. Bell, J. Am. Chem. Soc., 2013, 135, 12329-12337.

15 B. J. Trzesniewski, O. Diaz-Morales, D. A. Vermaas, A. Longo, W. Bras, M. T. Koper and W. A. Smith, J. Am. Chem. Soc., 2015, 137, 15112-15121. 
16 B. S. Yeo and A. T. Bell, J. Phys. Chem. C, 2012, 116, 83948400.

17 X. Lu and C. Zhao, Nat. Commun., 2015, 6, 6616.

18 J. Y. C. Chen, J. T. Miller, J. B. Gerken and S. S. Stahl, Energy Environ. Sci., 2014, 7, 1382-1386.

19 J. Ji, L. L. Zhang, H. Ji, Y. Li, X. Zhao, X. Bai, X. Fan, F. Zhang and R. S. Ruoff, ACS Nano, 2013, 7, 6237-6243.

20 G. Abellan, J. A. Carrasco, E. Coronado, J. P. Prieto-Ruiz and H. Prima-Garcia, Adv. Mater. Interfaces, 2014, 1, 1400184.

21 G. Chen, T. Wang, J. Zhang, P. Liu, H. Sun, X. Zhuang, M. Chen and X. Feng, Adv. Mater., 2018, 30, 1706279.

22 W. Zhang, J. Qi, K. Q. Liu and R. Cao, Adv. Energy Mater., 2016, 6, 1502489.

23 Y. Liu, X. Liang, L. Gu, Y. Zhang, G. D. Li, X. Zou and J. S. Chen, Nat. Commun., 2018, 9, 2609.

24 J. Y. Wang, L. L. Ji, S. S. Zuo and Z. F. Chen, Adv. Energy Mater., 2017, 7, 1700107.
25 X. Yang, C.-J. Wang, C.-C. Hou, W.-F. Fu and Y. Chen, ACS Sustainable Chem. Eng., 2018, 6, 2893-2897.

26 H. Wu, X. Lu, G. F. Zheng and G. W. Ho, Adv. Energy Mater., 2018, 8, 1702704.

27 W. X. Zhu, T. S. Zhang, Y. Zhang, Z. H. Yue, Y. G. Li, R. Wang, Y. W. Ji, X. P. Sun and J. L. Wang, Appl. Catal., B, 2019, 244, 844-852.

28 L. Hui, Y. Xue, B. Huang, H. Yu, C. Zhang, D. Zhang, D. Jia, Y. Zhao, Y. Li, H. Liu and Y. Li, Nat. Commun., 2018, 9, 5309.

29 J. F. Marco, J. R. Gancedo, M. Gracia, J. L. Gautier, E. Rios and F. J. Berry, J. Solid State Chem., 2000, 153, 74-81.

30 C. Yuan, J. Li, L. Hou, X. Zhang, L. Shen and X. W. D. Lou, Adv. Funct. Mater., 2012, 22, 4592-4597.

31 C. Xiao, Y. Li, X. Lu and C. Zhao, Adv. Funct. Mater., 2016, 26, 3515-3523.

32 Y. Liang, Q. Liu, A. M. Asiri, X. Sun and Y. He, Int. J. Hydrogen Energy, 2015, 40, 13258-13263. 